\title{
An Evaluation of Low Versus High Collaboration in Online Learning
}

\author{
David Wicks, Baine B. Craft, Donghun (Don) Lee, Andrew Lumpe, Robin Henrikson, Nalline Baliram, \\ Xu Bian, Stacy Mehlberg and Katy Wicks \\ Seattle Pacific University
}

\begin{abstract}
Researchers in a recent study found that online students' ability to self-regulate led to more focused attention and time on task, and in turn, these skills could lead to better learning. Given the need for more theoretical work in this area, as well as the potential practical benefits from the use of these pedagogical strategies, we sought to compare differences between high- versus low-collaboration teams in an online assignment to determine if higher levels of student-to-student collaboration led to higher levels of selfregulation or learning presence (forethought and planning, monitoring, strategy use, and reflection). Specifically, we explored how the use of high-collaboration technologies, such as Google Docs and Google Hangouts, impacted the level of learning presence students demonstrated while participating in a small group project. The low-collaboration group made minimal use of an asynchronous discussion forum for collaboration. Differences in collaboration were measured using student grades, peer evaluations, preand posttests, and community of inquiry surveys. In addition, quantitative content analysis and social network analysis were used to assess collaboration by examining learning presence in the two groups.
\end{abstract}

\section{Introduction}

In general, online course enrollments are growing faster than higher education enrollments, which may lead some, administrators included (Allen \& Seaman, 2014), to assume that online course quality is not an issue that needs to be addressed. However, online course quality continues to be a concern among university faculty and students (Akyol \& Garrison, 2008; Allen \& Seaman, 2013; Bolliger \& Inan, 2012; Bolliger, Inan \& Wasilik, 2014). Researchers have addressed quality concerns by conducting studies to help describe, explain, and predict how students learn best online, moving teachers toward a 
comprehensive online learning model that will improve quality (Anderson et al., 2001; Garrison, Anderson, \& Archer, 2000; Shea et al., 2013; Swan \& Shih, 2005). Despite recent work in this area, further studies are needed to address the numerous factors that could contribute to or detract from online course quality. One factor that remains relatively uninvestigated is the effect of student collaboration on student performance in and perception of online courses, especially courses that incorporate processfocused collaboration and product-focused knowledge construction (Shea et al., 2012; Shea et al., 2013). Therefore, the current study was designed to explore differences in student performance and perception between high- and low-collaboration assignments in two sections of the same online course where the high-collaboration course required small groups of online students to collaboratively write essays and make a presentation together. The effects of collaboration on learning were measured using student grades, peer evaluations, pre- and posttests, and the community of inquiry (CoI) framework. In addition, quantitative content analysis and social network analysis were used to explore evidence of learning presence in the two sections.

\section{Collaboration}

Collaborative learning is defined as the co-construction of a shared understanding of solutions to a problem (Dillenbourg \& Fischer, 2007; Roschelle \& Teasley, 1995). Course designers use the CoI theoretical framework to organize course content and assignments in a way that encourages students to "collaboratively engage in purposeful critical discourse and reflection to construct personal meaning and confirm mutual understanding” (Garrison, 2011, p. 15). A CoI is an educational community (e.g., students and teacher) engaged in purposeful discussion and reflection with the objective of addressing complex issues, resulting in a deep and meaningful learning experience (Garrison et al., 2000).

\section{Community of Inquiry}

A CoI facilitates this deep and meaningful learning through three interrelated elements: social presence, teaching presence, and cognitive presence. An instructor designs, facilitates, and provides direct instruction focused on inquiry (teaching presence). The course design facilitates student collaboration through assignments that promote positive affect, open interaction, and group cohesion (social presence). The assignments are inquiry based and tackle complex issues using the practical inquiry model to identify the problem through a triggering event, explore possible solutions, integrate all relevant ideas, and reach resolution (cognitive presence), which, because this is an iterative process, may include a recommendation for continued inquiry.

The CoI theoretical framework is over a decade old and well established in the literature (Garrison, Anderson, \& Archer, 2010; Swan \& Ice, 2010). A quick search of Google Scholar reveals that that the original Garrison et al. (2000) article has been cited over 2,000 times. Many studies have validated the framework presented in the seminal paper, while others have explored new directions (Garrison et al., 2010; Shea \& Bidjerano, 2009; Shea et al., 2012). Recently, Shea et al. (2013) reported that self-regulation, an important characteristic for successful online students, was underarticulated in the CoI model. In an effort to make the CoI framework more comprehensive, Shea and colleagues (2012) proposed an additional element (learning presence) to describe how students regulate their learning through self- and co-regulated processes, such as forethought and planning, monitoring, strategy use, and reflection.

\section{Learning Presence}

A course designed to enhance self-regulation may improve student satisfaction and achievement, representing a higher quality course. For example, Shea et al. (2013) found that learning presence was fostered through assigning students an instructional role in group discussions. Furthermore, the researchers revealed that students' ability to self-regulate led to more focused attention and time on task, and that in turn these skills could lead to better learning. The study called for further exploration into the specific roles of learners in online collaborative learning.

The present study attempts to build upon the aforementioned research by comparing the roles of learners in low- versus high-collaboration online courses. We define a low-collaboration course as one with a greater emphasis placed on personal meaning-making than mutual understanding. A group assignment in this type of course would be more cooperative than collaborative, where cooperative refers 
to a fixed division of labor in which students divide and work on tasks independently without significant input from the group. Student effort is assessed separately, meaning that there is no grade-related evaluation of group participation (Dillenbourg, 1999). A high-collaboration course assignment begins with a team charter (Palloff \& Pratt, 2007), whereby students agree on common goals at the beginning of the project and then continue to negotiate changes to those goals throughout the project (Dillenbourg, 1999). In our study, a high-collaboration assignment is defined as a small-group (team) activity in which the students do the work together. For example, several phases of the high-collaboration assignment in the current study required teams to edit a document together in a shared online writing environment (Google Docs) that tracks individual student contributions to the editing process through a document revision history. During each phase of the project, teams used a web conferencing tool (Google Hangouts) to plan, monitor, and devise strategy to complete the project. Online courses designed with high-collaboration activities with common goals, shared responsibility for knowledge construction, accountability through wiki-like environments, real-time meetings, and reflection through blogging may lead to a more egalitarian learning environment-meaning equivalent opportunities for students to demonstrate regulation of individual and collaborative learning (Wicks, Ellis, \& Lumpe, 2013). This planned selfregulation, self-monitoring, and self-reflection can result in positive learning outcomes (Means et al., 2009).

Positive learning outcomes were measured in the current study through a pre- and posttest on major content themes and the CoI survey (Arbaugh et al., 2008; Swan et al., 2008). Students completed the CoI survey at the end of the term in order to measure their perceived levels of teaching, social, and cognitive presence during the course. We hypothesized that students participating in a high-collaboration online course would demonstrate higher levels of self- and co-regulation (learning presence) than peers in a low-collaboration course. Higher learning presence may lead to greater satisfaction with the course and higher achievement. Quantitative content analysis was used to explore occurrences of learning presence in the two course sections.

\section{Social Network Analysis}

Finally, we employed social network analysis (SNA) as a method of inquiry to analyze student interaction data with respect to learning presence in the sections. Scholars have used SNA in the online learning context to understand individual and group dimensions of interactions. In the online learning presence context, students might have different roles in their contribution to the knowledge construction in the course in terms of prestige and influence (Shea et al., 2013). A student's prestige refers to the degree to which other students seek out that student for interaction (deLaat, Lally, Lipponen, \& Simons, 2007). The thoughts and opinions of high-prestige students may be considered more important than others in the class (Shea et al., 2013). Influence refers to the degree of a student's engagement in building or sustaining relationships with other students in the class, commonly measured by the number of discussion posts that student initiates to others (Shea et al., 2013). It should be noted that influence and prestige, though perhaps not mutually exclusive, are different concepts. For example, students who are highly engaged (influence) might not necessarily be the ones other students seek out for interaction (prestige), as their thoughts and opinions might not be considered more important than others in the class. In our study, we examine how students might have different levels of influence and prestige in their network depending on their level of learning presence (e.g., forethought and planning, monitoring, strategy use, and reflection). Our research questions were as follows:

1. Are there differences in student learning outcomes between the low- and high-collaboration groups as measured by a pre- and posttest and final course grade?

2. Are there differences in student perceptions of social, teaching, and cognitive presence as measured by the CoI survey?

3. Is there a difference in learning presence between low- and high-collaboration groups as measured by quantitative content analysis?

4. What is the relationship between students' learning presence in online activity and metrics reflected in social network analysis [e.g., in-degree (prestige) and out-degree (influence) centrality]? 


\section{Methods}

\section{Participants}

A total of 70 registered students were randomly assigned into one of two sections-either the comparison (low-collaboration) or the treatment (high-collaboration) group-of the same course cotaught by the same instructors. Of the 70 total students in the sections, 47 students completed the postassessment and survey required to participate in the study. The participants for the study $(N=47)$ consisted of 24 students in the low-collaboration (males $=7$, females $=18, M_{\text {age }}=32.09, S D_{\text {age }}=9.47$ ) group and 23 students in the high-collaboration (males $=5$, females $=18, M_{\text {age }}=29.65, S D_{\text {age }}=8.04$ ) group.

\section{Materials}

The participants were students in a fully online, graduate-level teacher education course. The purpose of the course was for students to learn how the theories of child and adolescent development apply practically in a classroom. This course was required for emerging educators seeking a teaching certificate in the state of Washington as well as a graduate degree in education. Both the high- and lowcollaboration sections received identical reading assignments, conducted similar discussions on weekly topics, and received identical lectures from the instructors via screencasts.

Pre-/Posttest. The students took a pretest and a posttest that aligned to the course objectives. This student self-report assessment contained the same six items for both the pretest and posttest administrations. The items required the students to reflect on their level of knowledge for each of the main content objectives being addressed in the course.

Community of Inquiry. The CoI survey is a psychometrically sound instrument developed to efficiently measure student perception of three interdependent domains within online classrooms (Arbaugh et al., 2008; Garrison et al., 2000; Swan et al., 2008). First, the teaching presence element measures student perception of course instruction, including organization, facilitation, and direct instruction. Second, the social presence element measures student perception of interaction with other learning community members, including affective expression, open communication, and group cohesion. Finally, the cognitive presence element measures student perception of the inquiry process organized using the practical inquiry model (Garrison et al., 2000). The CoI consists of 34 items, where questions 113 measure teaching presence, questions 14-22 address social presence, and questions 23-34 comprise cognitive presence.

Learning Presence. Learning presence components consisted of content analyzed in the group's phase-three discussions and course summary metareflective blog posts written by individual students. Shea et al. (2013) identified the following four categories of learning presence as an addition to the CoI components of teaching, social, and cognitive presence: forethought and planning, monitoring, strategy use, and reflection. Using the system outlined by Shea et al. (2013), two coders were trained using sample discussions and blog text. Each sentence was treated as an individual instance for coding. During the training, two additional non-learning-presence categories were created in order to categorize instances that did not fit the original learning presence scheme. The first, called "thoughts/facts," reflected instances where students simply repeated or recalled low-level facts. The second category, called "other," represented miscellaneous comments not directly pertaining to learning. Neither of these additional categories is hypothesized to be part of learning presence but rather represent simple, low-level tasks or recall. Once trained, the coders independently coded a set of text and obtained $74 \%$ agreement. After agreement was reached, a random sample of statements comprising $50 \%$ of the texts was selected for coding. Discussion and blogs from 18 low-collaboration students and 17 high-collaboration students were coded for learning presence.

Procedure

While the objectives were the same for both the high- and low-collaboration courses, the assignments and descriptions of how to meet these objectives varied based on section. Some of these changes were meant to simply balance the workload between the two groups for equity purposes while 
maintaining the rigor of the course and alignment to the objectives. However, one major assignment modification was used to allow one section of students to engage with a small team of classmates in a high-collaboration project while the same assignment in the other section required no collaboration with classmates. In both sections, the assignment contained four phases and was worked on the entire term.

Assignments were modified simply to maintain rigor and equity between the two groups. Both sections completed end-of-phase reflections; however, to balance the workload, the low-collaboration group was assigned a total of four reflections, while the high-collaboration group was assigned three reflections. Both sections completed a series of lesson plans and responded to prompts that followed. The low-collaboration section worked in preassigned pairs to complete the assignment; the assignment was designed to allow students to use a cooperative strategy in which they divided the assignment and worked separately to complete their parts before submitting the final work as a single document. It is important to note that the low-collaboration group did work in pairs rather than alone, as the instructors felt a moral obligation to allow this collaborative opportunity aligned to effective pedagogy to improve learning and did not want students to work in isolation. The students in the high-collaboration group completed this particular assignment individually to help equalize the workload.

In order to investigate the difference between high and low collaboration, a theory-to-practice project was designed differently for the two sections of the course. The purpose of this assignment was for students to demonstrate their emerging knowledge of the main theories of child development and connect these theoretical perspectives to implications for instruction. Students in the low-collaboration course worked individually to write a paper, due at the end of the course. Each paper was reviewed and scored by the instructors using a rubric. Students in the high-collaboration section completed the project in small groups of three or four students. Students in the high-collaboration group were instructed to work collaboratively for each of the four phases of the project.

While the objectives of the assignments were identical for both groups, the final product in the high-collaboration group was a presentation instead of a paper. The project was submitted in four phases. In phase one, students were expected to develop a team charter. Students first reviewed and responded to the prompts individually in Google Docs to ensure that each member had a voice in the process and product. They used Google Hangouts on Air to collaborate and develop a final version of the charter that incorporated ideas from all group members. Google Hangouts on Air was used because it allowed teams to record their meeting directly to YouTube and share a private link with the instructors. Both students' recording on Google Hangouts on Air and phase-one documents were reviewed by the instructors.

Instructions and prompts for phases two and three were strategically aligned with the particular theories of child development, which students explored and integrated during that time. Similar to the process in phase one, students were asked to respond to a set of prompts, individually at first, and then synchronously in collaboration with their group in order to create an outline in Google Docs for each phase. Students were required to reference the course texts, discussion blogs, and other resources they deemed appropriate to meet the requirements for each of the phases.

The final phase of the project encompassed students' understanding and knowledge of the topics explored in the course and was submitted in the form of an online presentation recorded using Google Hangouts on Air. The 15-20 min presentation reflected a collaborative effort that required all members to participate synchronously and reach resolution, without needing to be in the same location. Instructors reviewed the final presentation and scored it based on a rubric.

Upon completion of the assignments, the students in both sections of the course were given a preand posttest aligned to the course objectives. The purpose of this assessment was to measure students' perceptions of their content knowledge before taking the course and their growth in knowledge by the end of the course. There were six items on this self-report assessment. Students completed the preassessment during week one and completed the post-assessment during or after week ten.

To examine the relationship between learning presence and students' network position in terms of influence and prestige, we used centrality as the measurement for SNA. Centrality has been used as a measurement in the context of learning (Aviv, Erlich, Ravid, \& Geva, 2003; deLaat et al., 2007; Heo, Lim, \& Kim, 2010; Shea et al., 2013), and we followed Shea et al. (2013) by using it as a measurement of 
the level of students' influence and prestige in their network of communication. We used two measurements of centrality-in-degree centrality and out-degree centrality, which are counts of inbound and outbound ties (i.e., posts and responses of online discussions) of students. In-degree centrality was used as a proxy for prestige, which represents the degree to which students seek certain other students (those with high prestige) for interaction, because students with high prestige were acknowledged to have expressed more important opinions and thoughts than other students (deLaat et al., 2007; Shea et al., 2013). Out-degree centrality has been used as a proxy for influence, which represents the level of engagement with respect to building or sustaining relationships (Shea et al., 2013). Centrality measurements were calculated using UCINET software 6.0, and we plotted students' network positions based on their online discussions using NetDraw software.

\section{Results}

\section{Pre-/Posttest}

We assessed the effects of high- versus low-collaboration on student learning in two ways. First, we examined the difference between students' final grades. An independent samples $t$-test revealed no statistically significant difference between students' final grades in the high- and low-collaboration courses: $t(66)=1.05, p=.30$. Although not significant, students' final grades in the low-collaboration group $(M=94.86, S D=10)$ were lower and had greater variability than students in the high-collaboration group $(M=96.76, S D=3.60)$. Second, we gave students a pre-/posttest that assessed student knowledge of course content. The pretest was given at the beginning of the course, and the posttest was given after the final assignments had been completed. A mixed analysis of variance (ANOVA) was used to determine whether student scores differed across the pre- and posttest, between the high- and low-collaboration courses, and whether an interaction of pre-/posttest scores by course existed (see Table 1 for descriptive statistics). The ANOVA revealed no significant main effect between scores for students in the high- and low-collaboration groups as well as no significant interaction. However, a statistically significant main effect was observed for scores across the pre- and posttest measures: $F(1,52)=1109.05, p<.05, \eta^{2}=.96$ (see Figure 1). That is, students' knowledge of course content increased equivalently throughout both the high- and low-collaboration courses.

Table 1

Students' Pre- and Posttest Scores in the High- and Low-Collaboration Courses

\begin{tabular}{llll}
\hline & Group & $M$ & $S D$ \\
\hline Pretest & Low & 10.18 & 2.67 \\
& High & 10.08 & 2.51 \\
Posttest & Low & 26.11 & 3.14 \\
& High & 26.46 & 2.44 \\
\hline
\end{tabular}




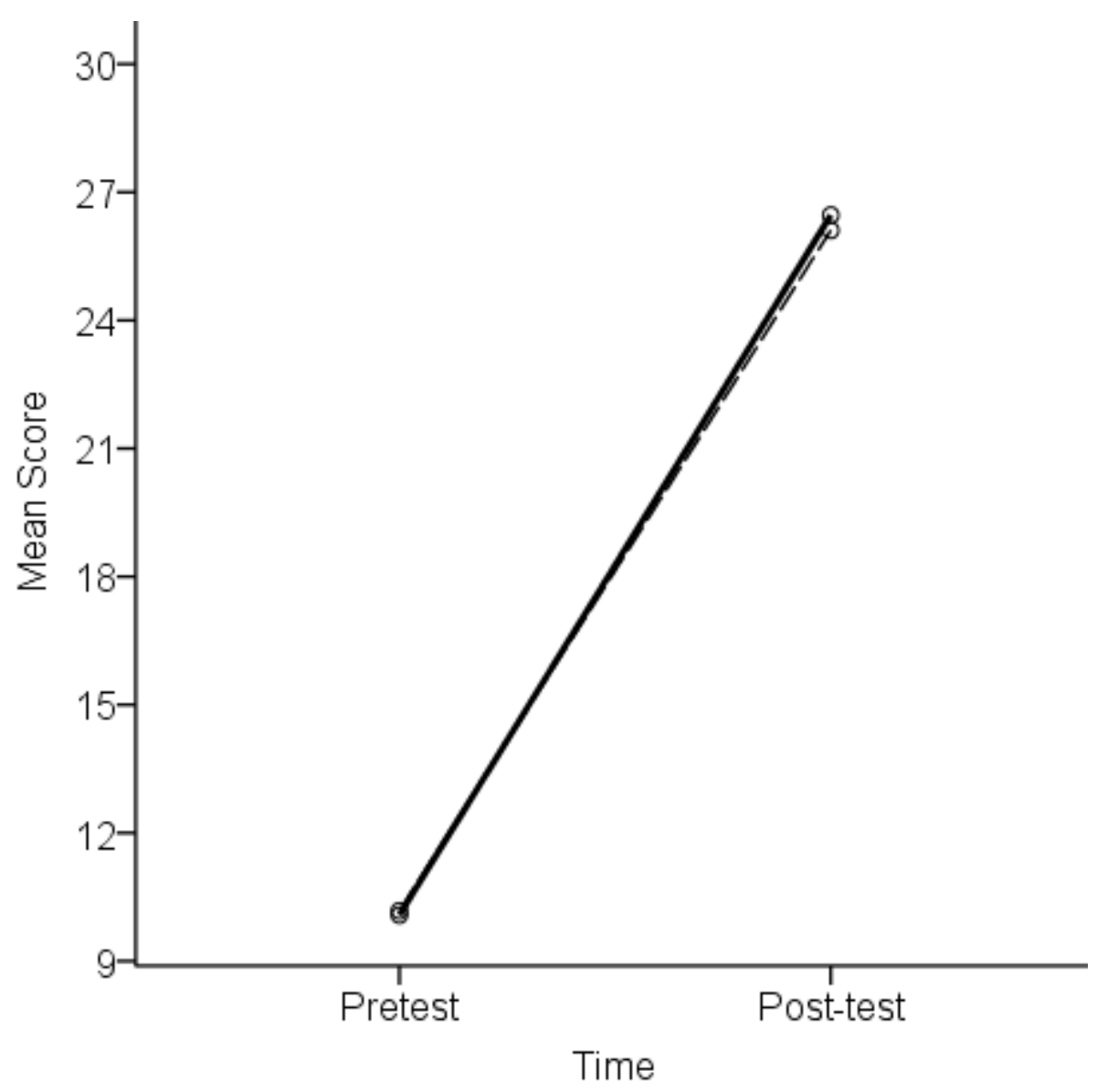

Figure 1. The dashed line represents the mean pre- and posttest scores from the low-collaboration group, and the solid line represents the mean pre- and posttest scores from the high-collaboration group.

\section{Community of Inquiry}

In order to assess students' experience of the course in terms of interactions with the instructor, other students, and course content, we used the CoI survey. An ANOVA was used to determine whether there was a significant main effect between the high- and low-collaboration courses, between the three factors of the CoI (i.e., teaching, social, and cognitive presence), and an interaction of courses by factor (see Table 2 for descriptive statistics). We found no significant main effect for courses or interaction, although we did observe a statistically significant difference in responses across teaching, social, and cognitive presence: $F(2,66)=7.25, p=.001, \eta^{2}=.18$ (see Figure 2, next page). More specifically, post hoc analysis using a Bonferroni adjustment revealed a significant difference between teaching and social presence $(p=.007)$.

Table 2 Community of Inquiry Scores for Students in the High- and Low-Collaboration Courses

\begin{tabular}{llcc}
\hline & Group & $M$ & $S D$ \\
\hline Teaching Presence & Low & 4.13 & .47 \\
& High & 3.83 & .67 \\
Social Presence & Low & 3.57 & .63 \\
& High & 3.67 & .63 \\
Cognitive Presence & Low & 3.90 & .52 \\
& High & 3.83 & .59 \\
\hline
\end{tabular}




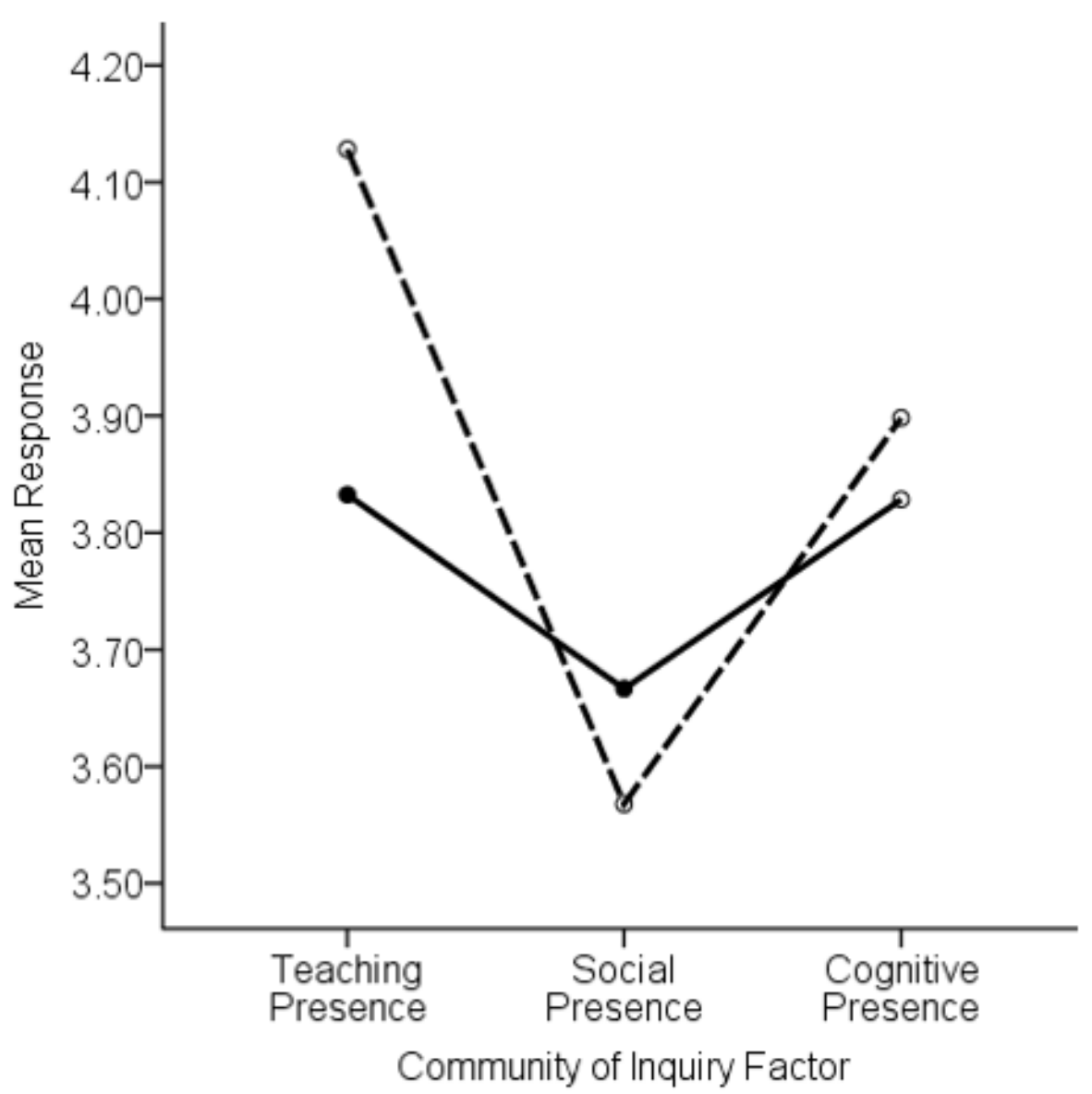

Figure 2. Mean community of inquiry responses. The low-collaboration students are represented by the dashed line and the high-collaboration students by the solid line.

\section{Learning Presence}

There were 2,086 coded instances of learning presence used during the low-collaboration discussions and 2,762 coded instances in the high-collaboration discussions. In the metareflective blogs, there were 445 coded instances of learning presence in the low-collaboration group and 303 in the highcollaboration group. Representative instances of learning presence components are shown below:

- Forethought and Planning-“"Yeah, let's do that for our opening and then that touches on most of the topics and then we can do paragraphs on the specific ones that we think are really important."

- Monitoring-“I think it is valuable to think about ways we can incorporate technology into the classroom as many students really connect with technology."

- Strategy Use-“"This approach makes common sense because if I start my lesson plan with the standards in mind, I can create it to build knowledge through activities and instruction with the students ultimately achieving understandings of the standards.”

- Reflection- "I have a tendency to think in terms of black and white, however throughout this quarter I have been struck by the varying shades of grey of child development.”

We found in the content analyses of the discussions that monitoring was the learning presence component most widely used by students in both the low- and high-collaboration sections, with strategy use being the second-most-used component (see Figure 3). There was little use of reflection. In the postcourse, metareflective blogs, the pattern was repeated, but there was a higher proportion of reflection over the phase-three discussions (see Figure 4). 
Since the data violated parametric assumptions, nonparametric comparisons between low- and high-collaboration groups were conducted separately on discussions and blogs. In the discussions, a significant difference was found in the forethought and planning learning presence component with the high-collaboration group (mean rank 27.0), showing more use of this component than the lowcollaboration group (mean rank 9.5) $(\square=27.67, p=.001)$. Also in the discussions, the low-collaboration group showed a higher use of reflection (mean rank 27.5) than the high-collaboration students (mean rank 12.2) $(\square=10.97, p=.001)$. There were no significant differences between the low- and highcollaboration sections in their use of learning presence components during the postcourse, metareflective blogs.

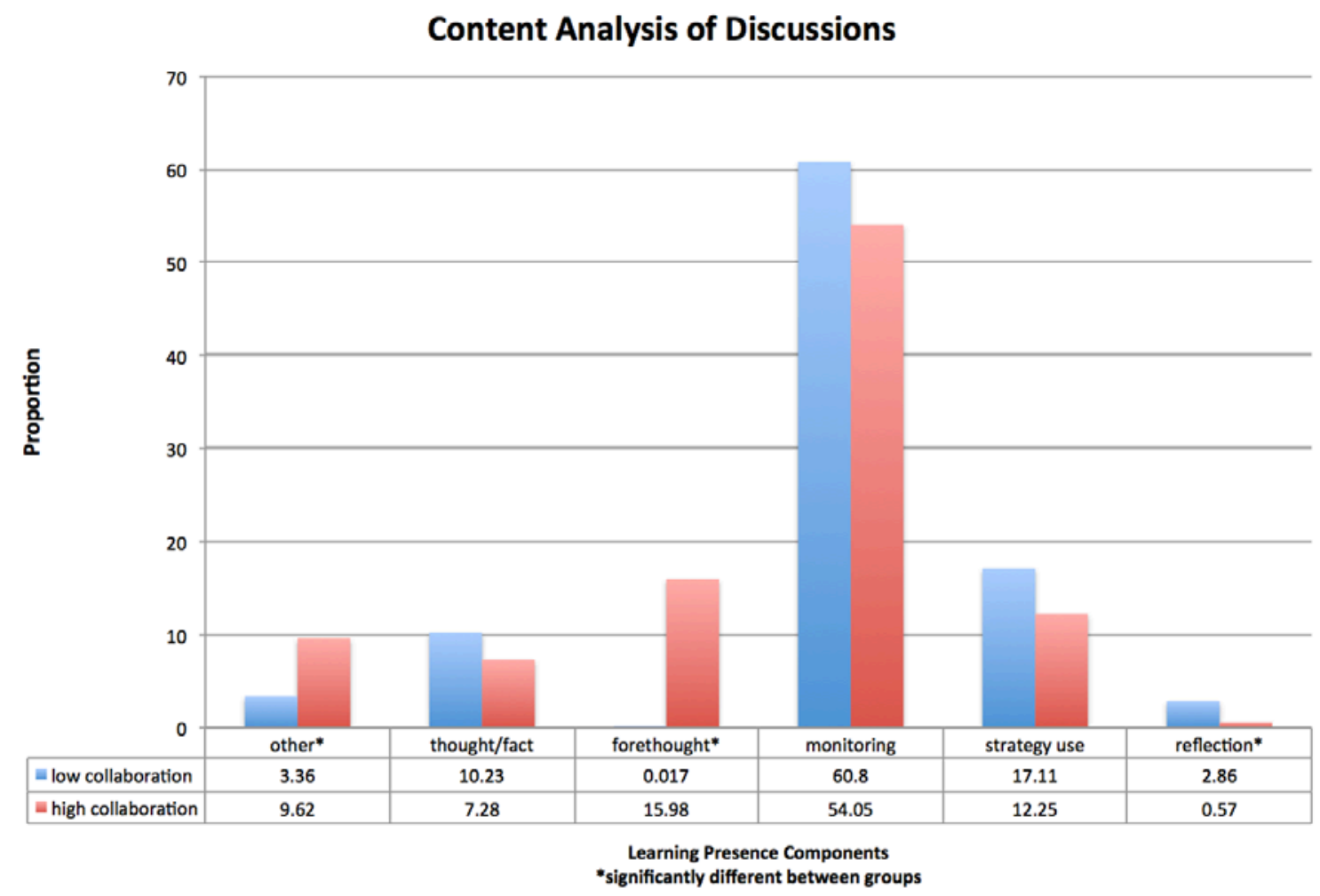

Figure 3. Learning presence components in the discussions. 


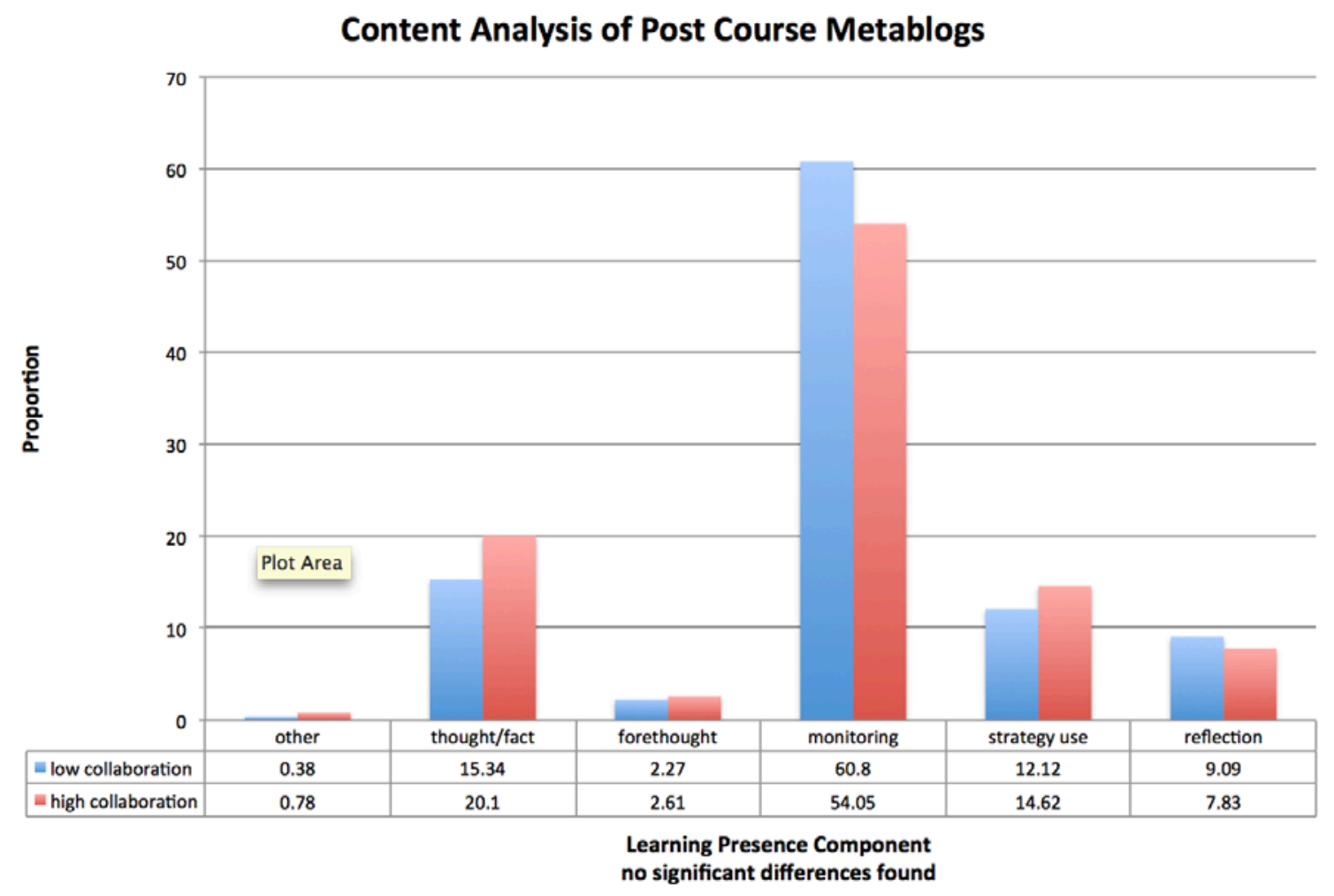

Figure 4. Learning presence components in the metareflective blogs.

\section{Social Network Analysis}

To examine the relationship between students' learning presence in online activity and centrality, prestige, and influence, we ran pairwise correlations with the measurements of the constructs of learning presence and social networks. As shown in Table 3, Freeman degree centrality, the sum of in-degree centrality and out-degree centrality, did not show any statistically significant correlation with any of the variables. However, when we divided the centrality measure into in-degree centrality (prestige) and outdegree centrality (influence), we found statistically significant correlations between certain centrality measures and online learning presence measurements. Specifically, prestige (in-degree centrality) showed a statistically significant and positive correlation with overall learning presence $(r=.53)$, forethought and planning $(r=.66)$, and monitoring $(r=.51)$. Interestingly, influence (out-degree centrality) showed a statistically significant and negative correlation with overall learning presence $(r=\quad-.51)$, forethought and planning $(r=-.65)$, and monitoring $(r=-.52)$, while showing a statistically significant and positive correlation with strategy use $(r=.58)$.

Given the aforementioned results, we examined student interactions with network graphs to visualize the relationships (ties) of students with respect to online learning presence. Following the work of Shea et al. (2013), node size in the figures was scaled to correspond to the value (frequency) of each student's learning presence occurrences based on the analyzed discussion boards and Google Hangout sessions. In addition, analogous to a pairwise scatter plot, we established the network by plotting the coordinates of the nodes and ties based on the level of centrality ( $x$-axis) and the level of online learning presence (y-axis). Figure 5 shows the relationship between prestige (in-degree centrality) and overall learning presence. The size of each node represents the level of overall learning presence and shows an upward trend, meaning that students that showed higher levels of overall learning presence tended to show higher levels of prestige in their networks. In addition to overall learning presence, typologies of learning presence also showed a relationship with the network positions of students. As shown in Figure 6 , students with higher levels of forethought and planning tended to be positioned in higher levels of 
prestige in their networks. Figure 7 depicts the relationship between prestige and monitoring, where students with higher levels of monitoring tended to be positioned in higher levels of prestige in their networks.

Table 3

Bivariate Correlations, Means, and Standard Deviations for the Study Variables.

\begin{tabular}{|c|c|c|c|c|c|c|c|c|c|c|c|c|}
\hline Variable & 1 & 2 & & 3 & & 4 & & 5 & & 6 & 7 & 8 \\
\hline $\begin{array}{l}\text { Freeman } \\
\text { centrality }\end{array}$ & - & & & & & & & & & & & \\
\hline $\begin{array}{l}\text { Prestige } \quad \text { (in-degree } \\
\text { centrality) }\end{array}$ & .34 & - & & & & & & & & & & \\
\hline $\begin{array}{l}\text { Influence } \quad \text { (out-degree } \\
\text { centrality) }\end{array}$ & .01 & -.94 & ** & - & & & & & & & & \\
\hline $\begin{array}{l}\text { Learning } \\
\text { (combined) }\end{array}$ & .15 & .53 & * & -.51 & * & - & & & & & & \\
\hline $\begin{array}{l}\text { Forethought } \\
\text { planning }\end{array}$ & .14 & .66 & $* *$ & -.65 & * & .75 & $* * *$ & - & & & & \\
\hline Monitoring & .06 & .51 & $*$ & -.52 & $*$ & .96 & $* * *$ & .65 & $* *$ & - & & \\
\hline Strategy use & .18 & -.48 & & .58 & $*$ & .09 & & -.22 & & -.03 & - & \\
\hline Reflection & .02 & .27 & & -.28 & & .30 & & .16 & & .30 & -.01 & - \\
\hline$M$ & 32.06 & 18.59 & & 13.47 & & 176.71 & & 31.24 & & 106.18 & 23.94 & 1.12 \\
\hline$S D$ & 3.88 & 11.07 & & 10.41 & & 72.81 & & 22.73 & & 48.70 & 14.52 & 1.22 \\
\hline
\end{tabular}

${ }^{*} p<.05 ;{ }^{* *} p<.01 ; * * * p<.001$.

Figures 8 to 11 depict the relationship between influence (out-degree centrality) and levels of online learning presence. Figure 8 shows the relationship between influence and overall learning presence, where students with lower levels of learning presence tended to be positioned in higher levels of influence in their networks. Figure 9 shows the relationship between influence and forethought and planning, where students with lower levels of forethought and planning tended to be positioned in higher levels of influence in their networks. Figure 10 depicts the relationship between influence and monitoring, where students with lower levels of monitoring as an online learning presence tended to be positioned in higher levels of influence in their networks. Figure 11 shows the relationship between influence and strategy use, where students with higher levels of strategy use as an online learning presence tended to be positioned in higher levels of influence in their networks. 


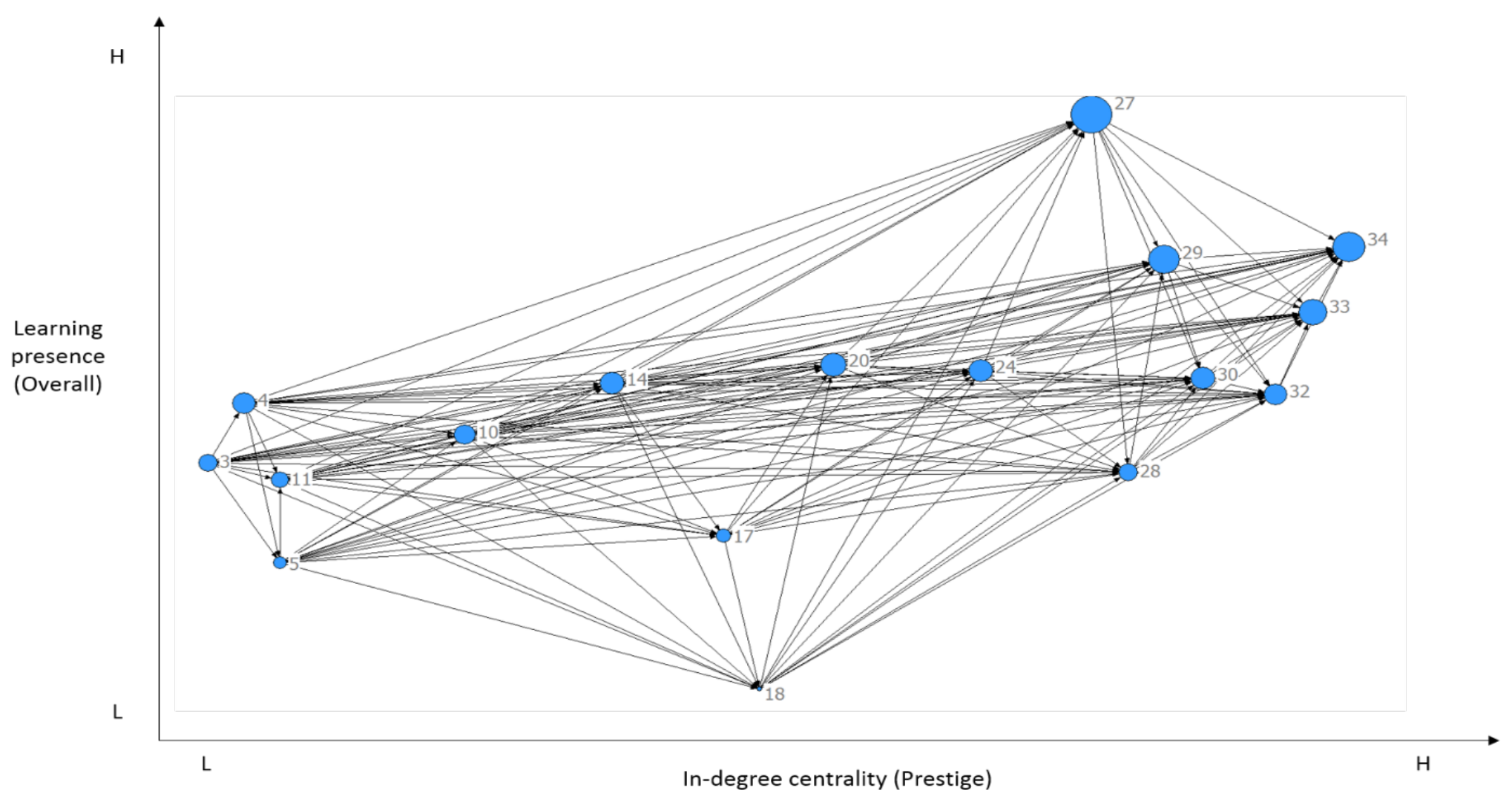

Figure 5. In-degree centrality (prestige) and online learning presence (overall)

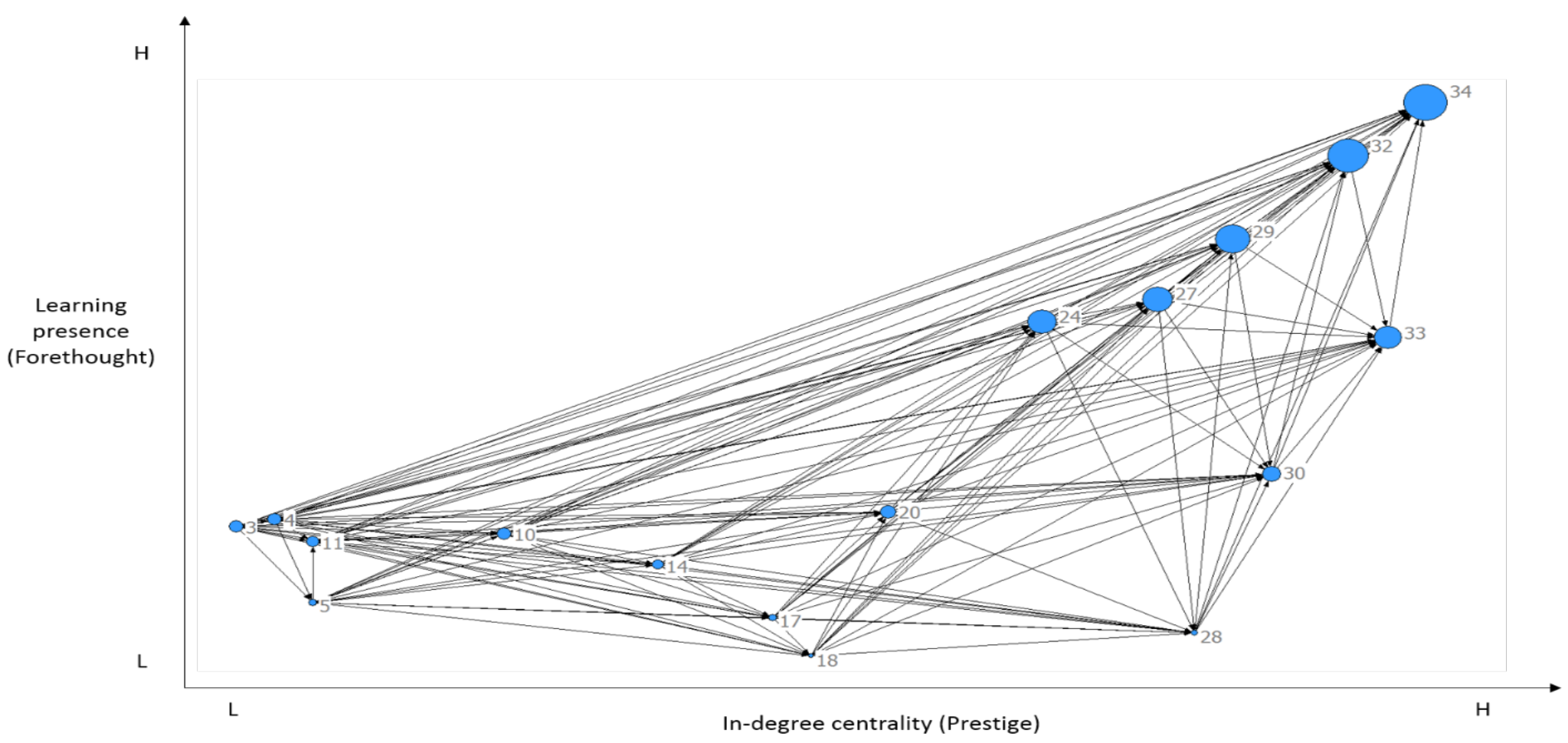

Figure 6. In-degree centrality (prestige) and online learning presence (forethought and planning) 


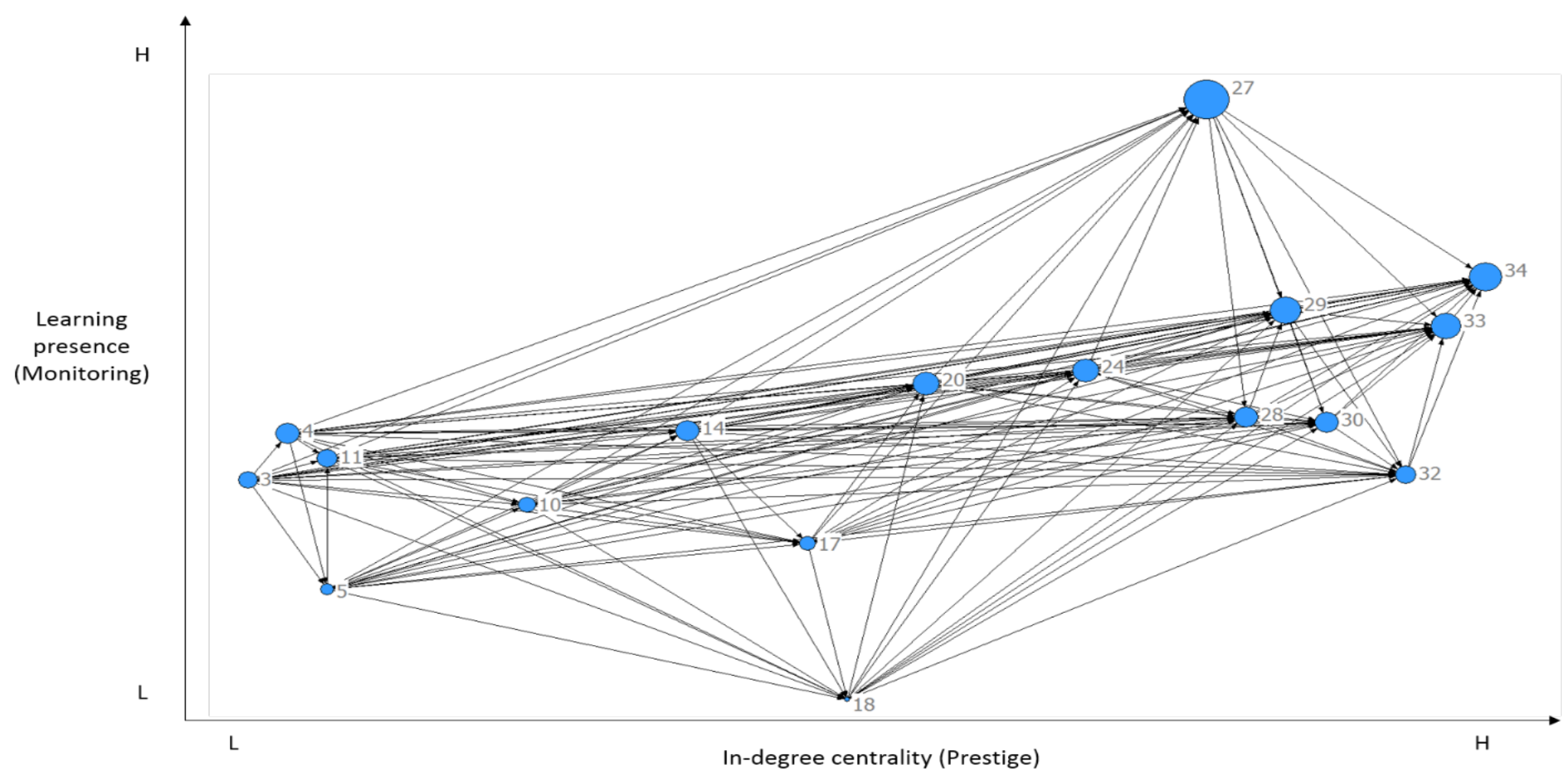

Figure 7. In-degree centrality (prestige) and online learning presence (monitoring)

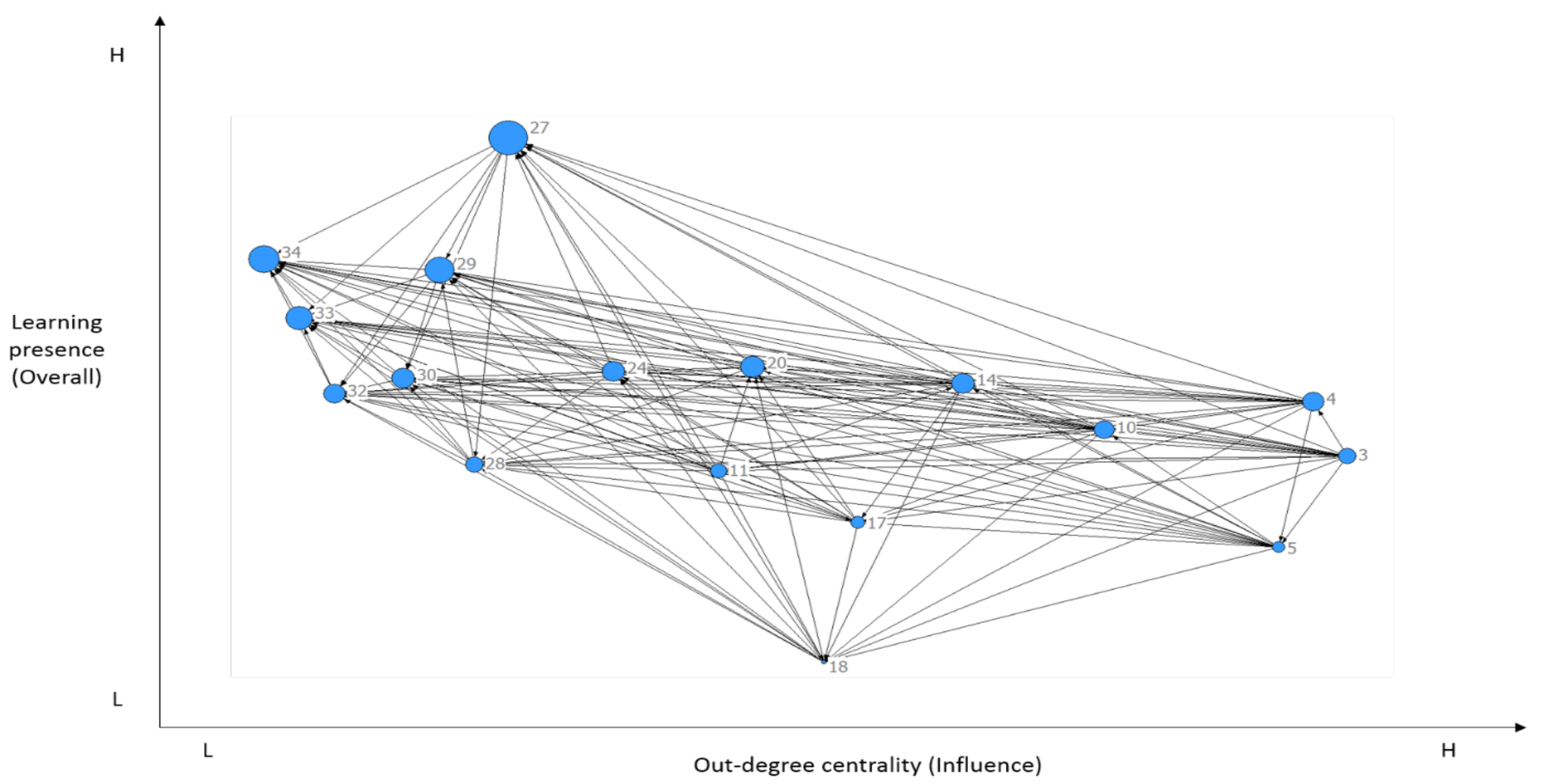

Figure 8. Out-degree centrality (influence) and online learning presence (overall) 


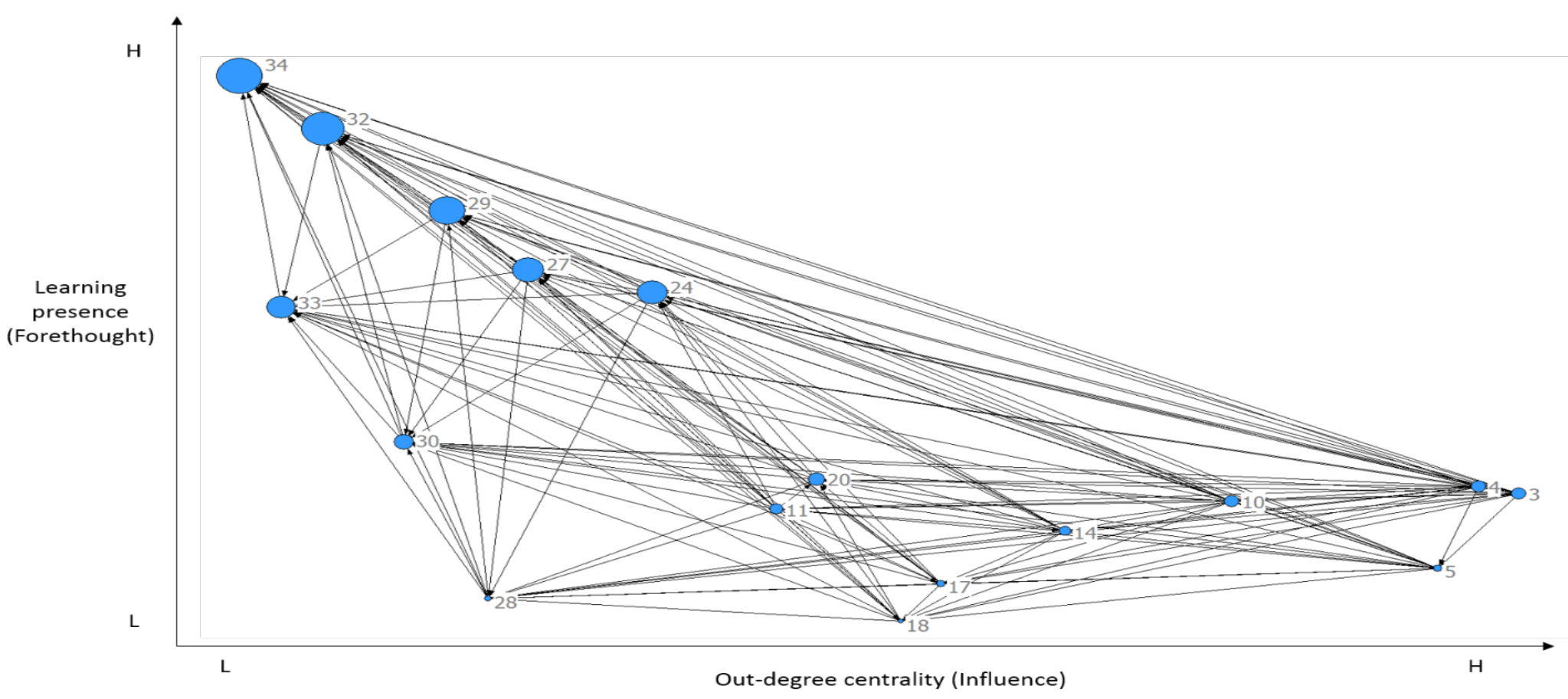

Figure 9. Out-degree centrality (influence) and online learning presence (forethought and planning)

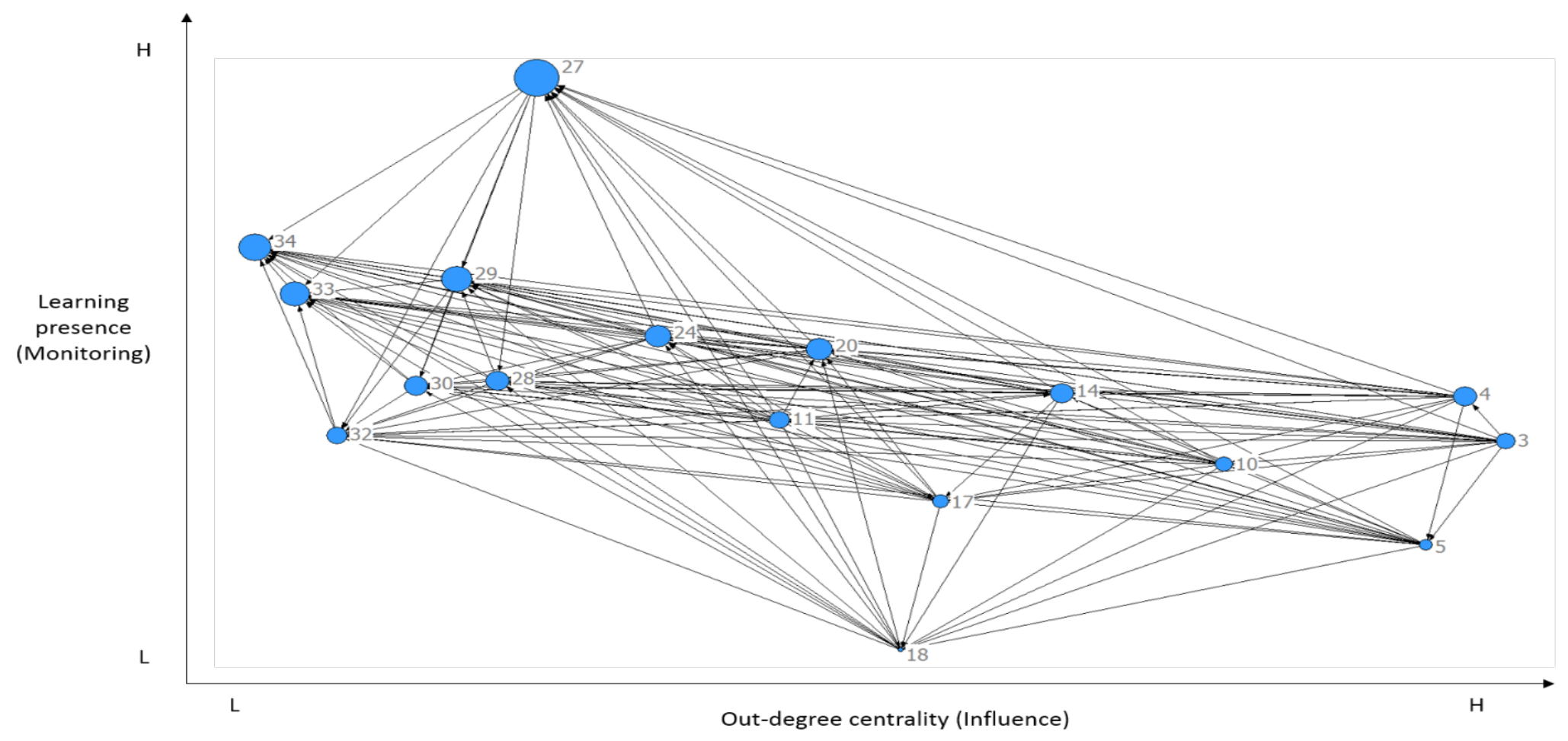

Figure 10. Out-degree centrality (influence) and online learning presence (monitoring) 


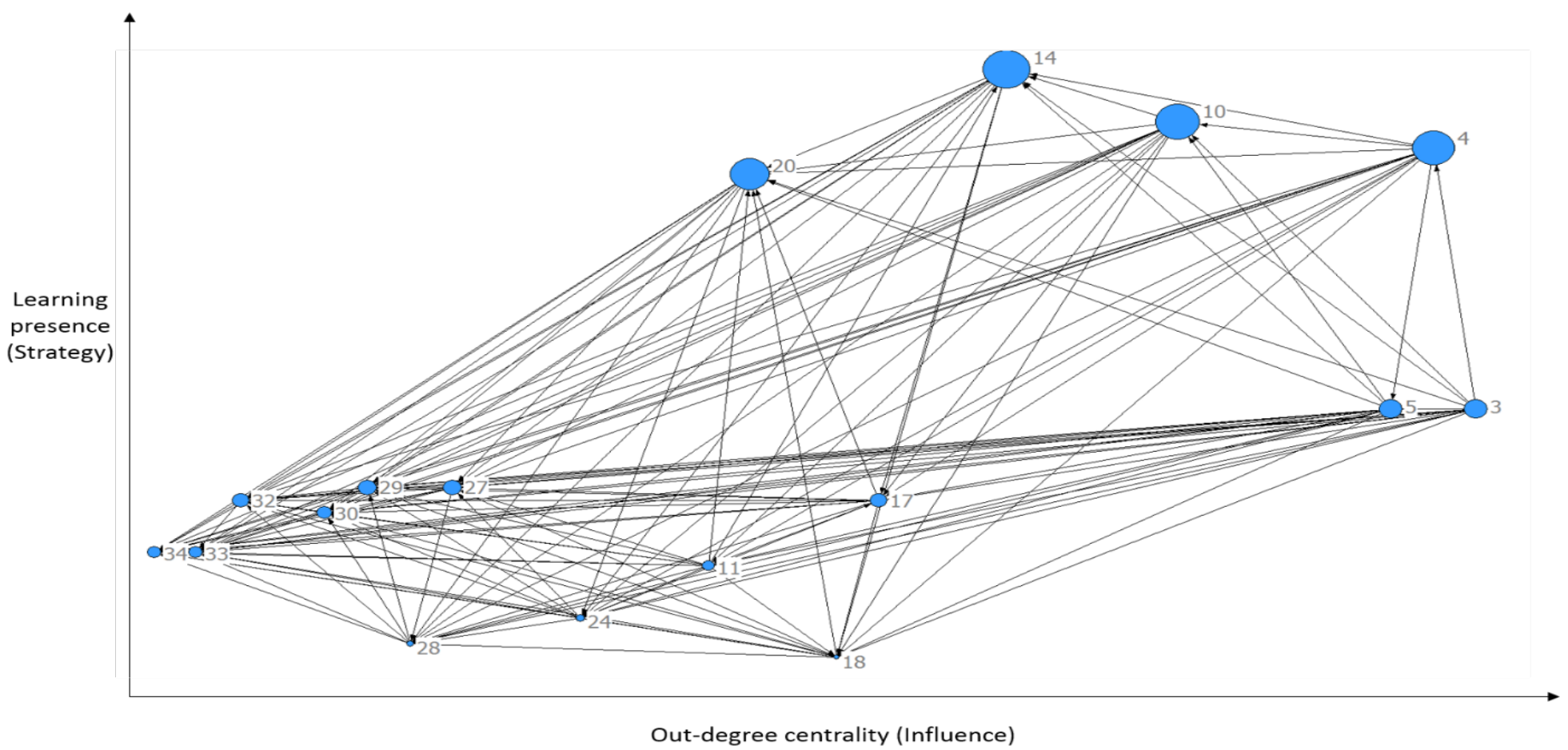

Figure 11. Out-degree centrality (influence) and online learning presence (strategy use)

To further examine whether learning presence had an effect on the levels of centrality of student positions in the network, we conducted a Wilcoxon-Mann-Whitney test (Mann \& Whitney, 1947), which is a nonparametric analog to the independent samples $t$-test. This test is used when a normally distributed interval variable is not assumed. We followed Shea et al. (2013) by rank ordering the students by their centrality measures (overall, in-degree, out-degree) and using a median split to divide the students into high and low levels of learning presence. First, as shown in Table 4, the results suggest that there is a statistically significant difference between the underlying distributions of the rank scores of in-degree centrality (prestige) based on high and low levels of overall learning presence (Mann-Whitney $U=12, z=$ $2.31, p=.02$ ). Specifically, students with high levels of overall learning presence showed higher prestige (in-degree centrality) than those with low levels of overall learning presence. Second, we found a statistically significant difference between the underlying distributions of the rank scores of in-degree centrality (prestige) based on high and low levels of forethought and planning (Mann-Whitney $U=12, z$ $=3.18, p=.001$ ). Specifically, students with high levels of forethought and planning showed higher prestige (in-degree centrality) than those with low levels of forethought and planning. Third, we observed a statistically significant difference between the underlying distributions of the rank scores of in-degree centrality (prestige) based on high and low levels of monitoring (Mann-Whitney $U=6, z=2.89, p=$ .002). Specifically, students with high levels of monitoring showed higher prestige (in-degree centrality) than those with low levels of monitoring. Fourth, the results revealed a statistically significant difference between the underlying distributions of the rank scores of in-degree centrality (prestige) based on high and low levels of strategy use (Mann-Whitney $U=14, z=-2.12, p=.036$ ). Specifically, students with low levels of strategy use showed higher prestige (in-degree centrality) than those with high levels of strategy use.

Next, as shown in Table 4, we compared the underlying distributions of the rank scores of outdegree centrality (influence) based on high and low levels of learning presence. First, the results revealed a statistically significant difference between the underlying distributions of the rank scores of out-degree centrality (influence) based on high and low levels of overall learning presence (Mann-Whitney $U=14, z$ 
$=-2.12, p=.036)$. Specifically, students with low levels of overall learning presence showed higher influence (out-degree centrality) than those with high levels of overall learning presence. Second, we found a statistically significant difference between the underlying distributions of the rank scores of outdegree centrality (influence) based on high and low levels of forethought and planning (Mann-Whitney $U$ $=4, z=-3.08, p=.001)$. Specifically, students with low levels of forethought and planning showed higher influence (out-degree centrality) than those with high levels of forethought and planning. Third, we observed a statistically significant difference between the underlying distributions of the rank scores of out-degree centrality (influence) based on high and low levels of monitoring (Mann-Whitney $U=7, z=$ 2.79, $p=.004$ ). Specifically, students with low levels of monitoring showed higher influence (out-degree centrality) than those with high levels of monitoring. Fourth, we found a statistically significant difference between the underlying distributions of the rank scores of out-degree centrality (influence) based on high and low levels of strategy use (Mann-Whitney $U=11, z=2.41, p=.015)$. Specifically, students with low levels of strategy use showed higher influence (out-degree centrality) than those with high levels of strategy use.

Table 4

Comparison of Levels of In-Degree (Prestige) and Out-Degree (Influence) Centrality Based on Levels (High and Low) of Learning Presence (Mann-Whitney U Test)

\begin{tabular}{|l|l|l|}
\hline & Prestige (in-degree) & Influence (out-degree) \\
\hline $\begin{array}{l}\text { Overall } \\
\text { learning } \\
\text { presence }\end{array}$ & $\begin{array}{l}\text { High learning presence ranked higher in centrality } \\
\left(U=12, Z=2.31^{*}, n_{1}=8, n_{2}=9\right)\end{array}$ & $\begin{array}{l}\text { Low learning presence ranked higher in centrality } \\
\left(U=14, Z=-2.12^{*}, n_{1}=8, n_{2}=9\right)\end{array}$ \\
\hline $\begin{array}{l}\text { Forethought } \\
\text { and planning }\end{array}$ & $\begin{array}{l}\text { High forethought ranked higher in centrality }\left(U=3.18^{* * *}, n_{1}=8, n_{2}=9\right) \\
3, Z=1\end{array}$ & $\begin{array}{l}\text { Low learning presence ranked higher in centrality } \\
\left(U=4, Z=-3.08^{* * *}, n_{1}=8, n_{2}=9\right)\end{array}$ \\
\hline Monitoring & $\begin{array}{l}\text { High learning presence ranked lower in centrality } \\
\left(U=6, Z=2.89^{* * *}, n_{1}=8, n_{2}=9\right)\end{array}$ & $\begin{array}{l}\text { Low learning presence ranked higher in centrality } \\
\left(U=7, Z=-2.79^{* * *}, n_{1}=8, n_{2}=9\right)\end{array}$ \\
\hline Strategy use & $\begin{array}{l}\text { Low learning presence ranked higher in centrality } \\
\left(U=14, Z=-2.12^{*}, n_{1}=8, n_{2}=9\right)\end{array}$ & $\begin{array}{l}\text { High learning presence ranked higher in centrality } \\
\left(U=11, Z=2.41^{*}, n_{1}=8, n_{2}=9\right)\end{array}$ \\
\hline
\end{tabular}

${ }^{*} p<.05 ; * * p<.01 ; * * * p<.001$.

$U=$ Mann-Whitney $U$ test; $Z=$ Z-score. 


\section{Discussion}

According to our analysis, the type of section (i.e., high or low collaboration) did not impact student learning as measured by student final grades and the pretest/posttest. That is, student understanding and knowledge of course content increased equivalently across the sections with one possible exception. As previously mentioned, student final grades in the low-collaboration section were lower and more variable than the final grades observed in the high-collaboration section. Although not statistically significant, this result is interesting but difficult to explain. For example, this slight difference in grades could be the result of differences in the level of collaboration in the sections, but perhaps our measures were not sensitive enough to determine the degree to which collaboration impacted student learning. Although it is also possible that the observed difference in grades could also be the result of differences in assignments or other changes in the course that were not related to the type of collaboration in each course. It is, however, improbable that the difference is due to the sample characteristics, as students were randomly assigned to each section. In light of these results, further investigation of student learning in high- and low-collaboration situations where more sensitive measures are used is warranted.

We observed a difference in students' teaching and social presence scores on the CoI. Differences on the CoI potentially speak to the value students placed on the instructor in both the high- and lowcollaboration courses. In other words, students in both courses rated teaching presence higher than social presence. Although not significant and maybe due to small sample size, the trend in responses on both factors (i.e., teaching and social presence) between the two courses fit with the nature of each type of course. That is, students in the low-collaboration course perceived greater levels of teaching presence than students in the high-collaboration group. However, students in the high-collaboration course perceived a higher level of social presence than students in the low-collaboration section. This is fitting given that students in the low-collaboration group were not reliant on peers (due to independent assignments not requiring peer interaction) and were more reliant on instructor interaction and feedback, while students in the high-collaboration group relied on other students rather than the instructor to complete assignments. Given these findings, it would be beneficial to investigate the effects of collaboration on student interaction with faculty and peers.

Monitoring and strategy use were the most common learning presence components observed during phase three of the course for both the low- and high-collaboration groups. It was also observed that forethought and planning were commonly used by the high-collaboration group during the discussions. During the postcourse, metareflective blog posts, monitoring remained the most common learning presence component, although higher strategy use and reflection were observed by both groups. The highcollaboration section used more forethought in the discussions. This is fitting, as students in the highcollaboration section were divided into teams that collaborated on an essay and presentation, while the low-collaboration group participated in whole-class discussions leading to an individual paper. Highcollaboration students planned, coordinated, and assigned tasks to each other to complete these productfocused knowledge construction activities (Shea et al., 2012; Shea et al., 2013). The low-collaboration group displayed higher use of reflection in discussions. Course discussion prompts in the lowcollaboration section encouraged students to reflect on their teaching practices. Similar prompts were given to students in the high-collaboration section, but they were not asked to discuss these questions in the Hangouts, so there is no record of the reflections on these prompts. No real differences in learning presence were observed across the low- and high-collaboration groups in their postcourse blog posts.

Based on our SNA, it is noteworthy that the results of our study showed different patterns of students' learning presence depending on the levels of prestige and influence that they possessed in terms of the network of communication on discussion boards. Our findings mirror the correlations between overall centrality, prestige (in-degree centrality), influence (out-degree centrality), and the learning presence components. As learning presence increases, so does prestige. Conversely, as learning presence increases, influence decreases. Specifically, our results showed a positive relationship between prestige (in-degree centrality) and overall learning presence, forethought and planning, and monitoring. Results 
did not show a statistically significant correlation between prestige and strategy use but did show a statistically significant difference between rank scores of prestige of high- and low-strategy use. It is noteworthy that while students may seek students with high-prestige for forethought and planning and monitoring, they may not necessarily seek students of high-prestige for strategy use of learning. Prior studies have argued that students in a class may seek interaction with a student with high prestige since their thoughts may be considered important (deLaat et al., 2007; Shea et al., 2013). While we are not contending that high-prestige students' posting of strategy use is unimportant, we consider the possibility that students do not rely on high-prestige students when seeking knowledge on strategy use (e.g., advocating effort or focus, providing help to complete the online activity, etc.) - namely, tasks related to strategy use (e.g., advocating effort or focus, offering or providing help to complete the online activity, articulating gaps in knowledge) are completed by students with varying levels of prestige.

On the other hand, our results showed that there was a negative relationship between influence (out-degree centrality) and overall learning presence, forethought and planning, and monitoring. In addition, there was a positive relationship between influence and strategy use as a learning presence category. High influence (out-degree centrality) signifies that students are actively engaging in building or sustaining relationships with other students (Shea et al., 2013). The insight of our results is that students with a position of high influence in a network - meaning those with a higher level of engagement as indicated by their posting of more comments and thoughts on discussion boards than are posted by other students-may communicate knowledge with the purpose of strategy use more than other types of learning presence. This might imply that when there is a need to communicate the planning and implementing of the steps of tasks, students tend to engage more actively in the discussions of the action items (e.g., providing help to complete the online activity). While generalizations and cause-and-effect statements from the SNA findings cannot be made, it is possible that more capable peers are sought out for guidance, more capable peers dominate interaction, or less capable peers acquiesce to more capable peers.

By using SNA, we validated that SNA is a promising research method for examining theoretically grounded explanations of online learning, and build on existing knowledge about learning presence as an additional CoI construct (Shea et al., 2013). We extend our understanding of previous studies by showing not only that a position in a network of knowledge sharing and exchange has a relationship with the level of overall learning presence but also that the relationship may differ depending on the type of learning presence (e.g., forethought and planning, monitoring, or strategy use). Thus, the roles of learners in the context of their learning presence would be conditioned according to the their respective positions in the network of discussions.

In summary, students in both the high- and low-collaboration courses appeared to learn course content similarly; however, our measures of student learning (i.e., pre- and posttest, final grades) were not sensitive enough to detect differences between high- and low-collaboration courses. Future studies investigating the difference between high- and low-collaboration courses would benefit from using a standardized or validated assessment of student learning. In terms of CoI, while both courses valued the instructor, the type of course had a marginal impact on the value students placed on their peers. That is, students in the high-collaboration course valued their peers more than students in the low-collaboration course did. Therefore, designing courses that promote high collaboration could facilitate increased value in openness, meaning-making, and co-construction of knowledge. In light of our small sample size, future investigation of CoI where collaboration is manipulated is warranted. According to our analysis of learning presence, the high-collaboration course showed enhanced learning presence compared to the low-collaboration course. For example, students in the high-collaboration course displayed more forethought and planning (e.g., planned, coordinated, completed the activity) than students in the lowcollaboration course. Surprisingly, the low-collaboration group showed more reflection, but this observation could be due to a failure in design. That is, while we were able to capture students' reflections accurately in the low-collaboration group, our method did not allow us to accurately capture reflections in the high-collaboration course. Future studies of learning presence with a stronger course design focused 
on collaborative assignments and using an accurate method to capture forethought and planning, monitoring, and reflection should be conducted.

We invite future studies to build on our approach of using SNA to explore the relationship between CoI constructs, including learning presence, and social network attributes. While our study focused on centrality as an attribute of the social network of students' engagement in learning, there are potentially more insights that could be gained from examining other aspects of a network. For example, what is the relationship between learning presence and the density of a network of student communication? If we are reminded that density measures the degree of dyadic connection in a population, we can examine whether there is a difference of learning presence between two or more student groups that have different levels of density. For example, there may be differences in terms of learning presence between a class that is more focused on individual work and a class that has more teambased activities.

Another promising direction for future studies may be to examine the interaction of community of inquiry constructs and multiple social networks - namely, students might have multiple roles, and therefore may form multiple social networks, in a classroom setting when working on assignments and projects. For example, if the communication and relationships of students can be examined by an opinion exchange network and a student role network, how do these networks interact with each other, or differ, in terms of students' learning presence? Studies that integrate the various attributes of social network structures may be promising in the field of learning by providing valuable insights into how community of inquiry informs us about how learning occurs in particular settings. Finally, while it is beyond the scope of our study, another promising direction for research would be to explore the relationship between learning outcomes and prestige and influence, two characteristics of network positions of students in a learning environment. Such a study would shed light on whether students who had high prestige or influence did better in the course or experienced it differently.

Overall, further research is needed to better understand how to design collaborative online courses that enhance communities of inquiry and promote self- and co-regulation (learning presence) in a way that ultimately leads to higher quality courses.

\section{References}

Akyol, Z., \& Garrison, D. R. (2008). The development of a community of inquiry over time in an online course: Understanding the progression and integration of social, cognitive and teaching presence. Journal of Asynchronous Learning Networks, 12(3-4), 3-22.

Allen, I. E., \& Seaman, J. (2013). Changing course: Ten years of tracking online education in the United States. Babson Survey Research Group and Quahog Research Group.

Allen, I. E., \& Seaman, J. (2014). Grade change: Tracking online education in the United States. Babson Survey Research Group and Quahog Research Group.

Anderson, T., Rourke, L., Garrison, D. R., \& Archer, W. (2001). Assessing teaching presence in a computer conferencing context. Journal of Asynchronous Learning Networks, 5(2), 2-17.

Arbaugh, J. B., Cleveland-Innes, M., Díaz, S. R., Garrison, D. R., Ice, P., Richardson, J. C., \& Swan, K. (2008). Developing a community of inquiry instrument: Testing a measure of the community of inquiry framework using a multi-institutional sample. The Internet and Higher Education, 11(34), 133-136.

Aviv, R., Erlich, Z., Ravid, G., \& Geva, A. (2003). Network analysis of knowledge construction in asynchronous learning networks. Journal of Asynchronous Learning Networks, 7(3), 1-23. 
Bolliger, D. U., \& Inan, F. A. (2012). Development and validation of the Online Student Connectedness Survey (OSCS). The International Review in Open and Distance Learning, 13(3), 1-13.

Bolliger, D. U., Inan, F. A., \& Wasilik, O. (2014). Development and validation of the Online Instructor Satisfaction Measure (OISM). Educational Technology Society, 17(2), 183-195.

deLaat, M., Lally, V., Lipponen, L., \& Simons, R. (2007). Online teaching in networked learning communities: A multi-method approach to studying the role of the teacher. Instructional Science, 35(3), 257-286.

Dillenbourg, P. (1999). What do you mean by collaborative learning? In P. Dillenbourg (Ed.) Collaborative-learning: Cognitive and computational approaches (pp. 1-19). Oxford: Elsevier.

Dillenbourg, P., \& Fischer, F. (2007). Computer-supported collaborative learning: The basics. Zeitschrift Für Berufs- Und Wirtschaftspädagogik, 21, 111-130.

Garrison, D. R. (2011). E-learning in the 21st century: A framework for research and practice. New York: Routledge.

Garrison, D. R., Anderson, T., \& Archer, W. (2000). Critical inquiry in a text-based environment: Computer conferencing in higher education. The Internet and Higher Education, 2(2-3), 87-105.

Garrison, D. R., Anderson, T., \& Archer, W. (2010). The first decade of the community of inquiry framework: A retrospective. The Internet and Higher Education, 13(1), 5-9.

Mann, H. B., \& Whitney, D. R. (1947). On a test of whether one of two random variables is stochastically larger than the other. Annals of Mathematical Statistics, 18(1), 50-60.

Means, B., Toyama, Y., Murphy, R., \& Bakia, M. (2009). Evaluation of evidence-based practices in online learning: A meta-analysis and review of online learning studies. U.S. Department of Education.

Heo, H., Lim, K. Y., \& Kim, Y. (2010). Exploratory study on the patterns of online interaction and knowledge co-construction in project-based learning. Computers \& Education, 55(3), 1383-1392.

Palloff, R. M., \& Pratt, K. (2007). Building online learning communities: Effective strategies for the virtual classroom. San Francisco, CA: Jossey-Bass.

Roschelle, J., \& Teasley, S. D. (1995). The construction of shared knowledge in collaborative problem solving. In C. E. O’Malley (Ed.), Computer-supported collaborative learning. Berlin: SpringerVerlag.

Shea, P., \& Bidjerano, T. (2009). Community of inquiry as a theoretical framework to foster "epistemic engagement" and "cognitive presence" in online education. Computers and Education, 52(3), 543-553.

Shea, P., Hayes, S., Smith, S. U., Vickers, J., Bidjerano, T., Pickett, A., ... Shoubang, J. (2012). Learning presence: Additional research on a new conceptual element within the community of inquiry (CoI) framework. The Internet and Higher Education, 15(2), 89-95. 
Shea, P., Hayes, S., Smith, S. U., Vickers, J., Bidjerano, T., Gozza-Cohen, M., ... Tseng, C. H. (2013). Online learner self-regulation: Learning presence viewed through quantitative content and social network analysis. The International Review of Research in Open and Distance Learning, 14(3), 427-461.

Swan, K., Richardson, J. C., Ice, P., Garrison, D. R., Cleveland-Innes, M., \& Arbaugh, J. B. (2008). Validating a measurement tool of presence in online communities of inquiry. E-Mentor, 24(2), 112.

Swan, K., \& Ice, P. (2010). The community of inquiry framework ten years later: Introduction to the special issue. The Internet and Higher Education, 13(1-2), 1-4.

Swan, K., \& Shih, L. F. (2005). On the nature and development of social presence in online course discussions. Journal of Asynchronous Learning Networks, 9(3), 115-136.

Wicks, D., Ellis, A., \& Lumpe, A. (2013). The use of collaborative tools and student perception of social presence (pp. 2371-2379). In J. Harrington et al. (Eds.), Proceedings of World Conference on Educational Multimedia, Hypermedia and Telecommunications 2013, Victoria, BC, Canada: Association for the Advancement of Computing in Education (AACE). 